\title{
A INVASÃO DAS TECNOLOGIAS DE INFORMAÇÃO E COMUNICAÇÃO NAS ESCOLAS E O DIÁLOGO NECESSÁRIO
}

\author{
THE INVASION OF THE TECHNOLOGIES OF INFORMATION AND COMMUNICATION IN S \\ CHOOLS AND THE NECESSARY DIALOGUE
}

\section{LA INVASIÓN DE LAS TECNOLOGÍAS DE LA INFORMACIÓN Y LA COMUNICACIÓN EN} LAS ESCUELAS Y EL NECESARIO DIÁLOGO

\section{Graziela Cancio Siqueira ${ }^{1}$ Helena Amaral da Fontoura ${ }^{2}$}

\begin{abstract}
RESUMO: O presente artigo baseia-se em uma pesquisa de mestrado em educação que dialoga com professores egressos do curso de Ciências Biológicas de uma universidade localizada no estado do Rio de Janeiro, na qualidade de sujeitos mediadores entre os jovens, as demandas culturais e a estrutura escolar. O eixo é a influência das Tecnologias de Informação e Comunicação (TICs) em seus processos formativos e práticas pedagógicas. Há o destaque aqui para a importância da leitura de mundo (FREIRE, 2014) do educando, que se desdobra a partir do contexto sociocultural no qual ele está inserido, com ênfase na premência do diálogo que coadune esses elementos, objetivando a compreensão da invasão das TICs nas escolas, seja por via direta por intermédio dos recursos que emprega, ou indireta, em função da lógica que sua globalização produz, alterando linguagens e modalidades relacionais, construindo outros paradigmas. Discute-se também o entrincheiramento da instituição escolar e sua impermeabilidade aos fatores externos comboiados pelo seu material humano, o que desperta novamente a necessidade do diálogo para o entendimento dessas formas outras de interação.
\end{abstract}

PAlavraS-CHAVE: Estudo de egressos. TIC. Processos formativos. Práticas pedagógicas. Contexto sociocultural.

ABSTRACT: This article is based on a Masters research in education that engages teachers graduates of biological sciences from a university located in the state of Rio de Janeiro while subject mediators among youth, cultural demands and school structure, having as the influence of information and communication technologies (ICT) in their formative processes and pedagogical practices. There are the highlight here the importance of world of educating (FREIRE, 2014), that unfolds from the sociocultural context in which this falls, with emphasis on the urgency of the dialogue that line these elements aiming at understanding the invasion of ICT in schools, either by direct route through the resources they employ, or indirect, depending on the logic that your globalization produces by changing languages and relational modes, building other paradigms. It discusses also the auto protective posture of the institution and its imperviousness to external factors conveyed by his human material, which awakens again the need for dialogue to the understanding of these other forms of interaction.

KEYWORDS: Study of graduates. ICT. Formation processes. Pedagogical practices. Socio-cultural context.

\footnotetext{
${ }^{1}$ Graduada em Ciências Físicas e Biológicas pela Universidade Federal do Estado do Rio de Janeiro - UFRJ, Rio de Janeiro, RJ - Brasil. Atualmente, é professora da Secretaria Estadual de Educação do Rio de Janeiro e do Centro Educacional Alzira Bittencourt. E-mail: grasiqueira@bol.com.br.

${ }^{2}$ Pesquisadora CNPq - Cientista da FAPERJ - Procientista UERJ/FFP (Universidade do Estado do Rio de Janeiro - Faculdade de Formação de Professores)

Recebido em: 02/07/2015 - Aprovado em: 18/12/2015.
}

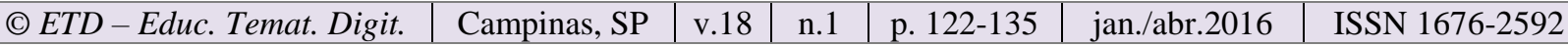


RESUMEN: Este artículo se basa en una investigación de la maestría en educación que dialoga con maestros graduados del curso de Ciencias Biológicas de una universidad ubicada en el Estado de Río de Janeiro, como mediadores entre los jóvenes, las demandas culturales y la estructura de la escuela, teniendo como eje la influencia de las Tecnologías de la Información y la Comunicación (TIC) en sus procesos formativos y en sus prácticas pedagógicas. Hay que resaltar aquí la importancia de la lectura de mundo (Freire, 2014) del estudiante, que se despliega desde el contexto sociocultural en que éste se inserta, con énfasis en la urgencia del diálogo que une estos elementos, con el objetivo de comprender la invasión de las TIC en las escuelas, ya sea por vía directa a través de los recursos que emplean, o indirecta, en función de la lógica que la globalización produce, cambiando lenguajes y modos relacionales, construyendo otros paradigmas. Discute, también, el afianzamiento de la escuela y su impermeabilidad a factores externos, escoltada por su material humano, que despierta, una vez más, la necesidad de diálogo para la comprensión de estas otras formas de interacción.

PALABRAS CLAVE: Estudio de la formación de graduados. TIC. Procesos. Prácticas pedagógicas. Contexto socio-cultural.

\section{INTRODUÇÃO}

A intenção deste artigo é ressaltar a importância do contexto sociocultural para a compreensão de fenômenos observados nos ambientes escolares, viabilizando diálogos que conjecturem possíveis ingerências em tais meios. Trata-se do escopo de uma pesquisa de mestrado em andamento, que investiga com professores egressos do curso de Ciências Biológicas de uma instituição pública de ensino do Rio de Janeiro a influência das Tecnologias de Informação e Comunicação (TICs) em seus percursos formativos e práticas pedagógicas.

A escolha dos professores egressos de Ciências Biológicas traz um recorte relacionado à estrutura da pesquisa e tê-los como sujeitos busca legitimar a investigação, pois os profissionais participantes representam a universidade no mercado de trabalho, e nessa oportunidade, estariam municiando-a de elementos ativos, que em tempo real se configuram, os mesmos que futuramente poderão atuar como parâmetro para os processos de formação exercidos pela própria instituição, compondo o trânsito de conhecimentos e aproximando instâncias que comumente não interagem a contento.

Uma característica marcante no campo da pesquisa é a manutenção de programas de sondagem e o relacionamento com os ex-alunos. A iniciativa praticada por Fernandes (2011), por exemplo, corresponde a uma investigação sobre a inserção profissional dos egressos, que resultou em aspectos quantitativos e qualitativos sobre o assunto. Constatou, com base nos depoimentos dos mesmos, que os primeiros anos da carreira são considerados críticos, o que ressalta a importância do papel da universidade na mobilização desses sujeitos ao acessar suas experiências, não esgotando a participação na diplomação. Além disso, nas palavras da mesma autora: 
O trabalho desenvolvido com professores egressos é enriquecedor tanto para estes sujeitos quanto para a universidade. O contato com ex-alunos permite a avaliação dos conteúdos, práticas e métodos dos cursos. A universidade consegue retorno quanto à qualificação dos seus profissionais, identifica se houve uma boa formação, se foi eficaz e quais as dificuldades encontradas, para que possa dar maior assistência a esses profissionais e até mesmo mudar o currículo, se necessário, para que outras pessoas possam ter a oportunidade de uma melhor formação com um currículo mais abrangente. (FERNANDES, 2011, p. 70.)

A Residência Pedagógica é um programa que apresenta um propósito similar; corresponde a um grupo que também reúne egressos de todas as licenciaturas e estabelece trocas de experiências sobre percursos de vida e de trabalho. Os escritos produzidos nos encontros recirculam e discutem concepções importantes ao fortalecimento docente. Em 2011 a culminância do trabalho traduziu-se em um livro cujos professores-autores puderam expor as versões de suas práticas, em um registro documental de suas vozes. Sobre a eficácia do projeto, concordamos com Fontoura (2011, p. 317), que enuncia:

Construir e reconstruir um professor consciente de seu papel social, autônomo e crítico, depende de condições de disponibilidade externa e interna para dialogar sobre o que fazemos, falar sobre o desejo de transformar a realidade em que vivemos e trabalhamos, buscar as questões que trazemos em nós e que nos mobilizam na direção de novos e mais altos voos.

A experiência relatada por Fontoura (2011) contribui para o desenvolvimento profissional docente à medida que, além de provocar a reflexão, permite a mescla dos saberes de suas práticas aos referenciais acadêmicos, transpondo as barreiras do isolamento, do qual muitos professores se queixam.

O Departamento de Ciências da mesma universidade desenvolve uma política de relacionamento e mantém vinculado um grupo de egressos de Ciências Biológicas, que inclui como participantes professores regentes da escola básica, especialmente na rede pública de ensino. Em encontros periódicos eles têm a oportunidade de importar e exportar mecanismos pedagógicos e práticos, êxitos e desacertos, fomentando a construção de sua autonomia profissional.

Além de propiciarem os benefícios citados no que diz respeito às expertises, os contatos promovidos por meio dos programas descritos podem ser úteis também como ricos espaços de debate e crescimento pessoal, pois o manejo das vivências pode indicar estratégias e metodologias que facilitem a relação do professor com os assédios impostos ao longo de sua trajetória. A partir dos fluxos apontados, os docentes se destacam como peças-chave no estudo já referido, o que se deve provavelmente ao fato de encontrarem-se em um posicionamento limítrofe, mediando demandas oriundas dos estudantes (cambiadas no arcabouço cultural que frequentam), da escola e da própria sociedade.

Interessa aqui discutir a invasão das TICs como fenômeno a ser analisado diante das transformações instrumentais ou ideológicas que possam promover nos espaços educativos. Para tanto, torna-se imprescindível uma fundamentação teórica que apoie uma aproximação à perspectiva dos envolvidos na análise, ou seja, para que a infiltração das TICs possa ser 
pensada como algo consideravelmente importante a ser investigado é igualmente importante reconhecermos as condições em que se instalam seus processos de expansão e suas possíveis apropriações. A investigação em questão é de cunho qualitativo, de caráter exploratório e a metodologia consiste na obtenção de dados por meio de entrevistas semiestruturadas.

Avaliações isoladas e estanques podem depreciar o potencial do conjunto. Portanto, para que se estruture algum parecer sobre a influência das TICs nos seus percursos formativos e no seu trabalho, pode ser proveitosa ao docente a revisitação dos contextos nos quais os componentes da análise estão imersos. Dessa forma, algumas indagações sobressaem demonstrando a polivalência do tema. Assim, no que tange às tecnologias, por exemplo, que subjetividades têm sido forjadas nos sujeitos expostos? Há influência das TICs na cultura? Essas e muitas outras problematizações retratam a necessidade de reflexões, que principalmente no âmbito educacional põem em diálogo alguns de seus atores.

A instituição escolar acolhe demandas extremamente heterogêneas e em geral concentra em seus meandros pedagógicos artifícios que ressaltam a padronização e a uniformização, formatando diferenças e requerendo de seus frequentadores enquadramento e doutrinação. Tais procedimentos podem contribuir gradativamente para a blindagem da escola, tornando-a pouco permeável às transições culturais e comportamentais da sociedade. Esse abarreiramento tende a alargar distâncias ou até mesmo a rechaçar os estudantes, pois não raramente suas engrenagens são movimentadas por atividades desconectadas e desafinadas em relação ao que os mesmos vivenciam socialmente.

É bastante incauta, no entanto, a ideia de que a escola estaria preparada para sintonizar suas atividades à grande quantidade de inovações tecnológicas que lhe afetam, por exemplo, mas se omitir ante a importância delas e de outras possibilidades potencialmente pedagógicas pode significar a anulação de canais de comunicação com seus jovens integrantes, uma provável negação à experiência.

\section{A PARTICULARIZAÇÃO DA LEITURA DE MUNDO}

Abolir a ideia de que no espaço educativo existe o formador e o formado pode propiciar relações mais flexíveis com os educandos, viabilizando a discussão sobre a relevância dos conteúdos, a inclusão destes na realidade social daqueles sujeitos e a analogia com os conhecimentos trazidos por todos. O enquadramento e a contextualização daquilo que se oferece nos componentes curriculares aproxima conhecimentos que até certo ponto parecem inócuos ao seu efeito real.

Aproveitar o que culturalmente é cultivado pelo aluno em ambientes não escolares pode vincular e estabelecer uma relação de sentido com a função da escola. A aproximação das linguagens e a cessão da liberdade de expressão dos hábitos e das atitudes referentes ao seu repertório social podem contribuir para que se faça o exercício crítico e opinativo, conduzindo à reflexão. 
Freire (2014) se posiciona como esperançoso diante da consciência do inacabamento humano como geradora de impulsos de intervenção, quando enfatiza que a certeza da incompletude motiva e incita diversas ambições, indicando que elas seriam motivadas pela ideia de que o indivíduo deve interferir no mundo como agente e não como objeto, e que a neutralidade na relação com o mundo é impossível. Corroborar com a noção de que a consciência da inconclusão é precursora da educabilidade, reforça a liberdade na construção da autonomia, pois para o autor, "estar no mundo necessariamente significa estar com o mundo e com os outros." (FREIRE, 2014, p. 57.)

A importância dessa intercambialidade é levantada por Freire (2014) ao afirmar também que o respeito à curiosidade do educando e o interesse pela leitura dele de mundo, que incluem as formas como o sujeito se vê inserido nos contextos que compõe, precedem a leitura da palavra. A rejeição do professor à leitura de mundo do aluno e o desconhecimento dos elementos que o cercam e afetam pode se traduzir em um obstáculo à experiência do conhecimento e comprometer a relação professor-aluno. Respeitar e entender, no entanto, não significam obrigatória concordância, mas a valorização de aspectos intrínsecos aos estudantes que de várias maneiras influem nos processos pedagógicos, podendo auxiliar na validação dos saberes discentes, afiná-los com a sua cultura pregressa e amplificar suas vozes.

Negociar as regras organizadoras dos espaços-tempos escolares pode favorecer a construção da autonomia e reforçar a autoridade docente, visto que a postura dialógica promove a reflexão. A eleição do momento adequado para o emprego pedagógico de recursos tecnológicos, por exemplo, pode significar uma das oportunidades do exercício da leitura de mundo (FREIRE, 2014), pois trazer à tona e discutir a relevância de tais recursos e o que a partir deles pode ser experienciado, revolve também a capacidade de tomada de decisões, agregando mais segurança às escolhas, já que

(...) a autonomia, enquanto amadurecimento do ser para si, é processo, é vir a ser. Não ocorre em data marcada. É neste sentido que uma pedagogia da autonomia tem de estar centrada em experiências estimuladoras da decisão e da responsabilidade, vale dizer, em experiências respeitosas da liberdade. (FREIRE, 2014, p.105.)

Quando consideramos a tecnologização e a virtualidade como elementos a serem aliados aos paradigmas educacionais e analisamos esses aspectos como precedentes culturais dos alunos, estamos reconhecendo a relevância de tais temas na particularização da leitura de mundo, o que convoca os educadores à atenção.

Estamos diante de uma reconfiguração cultural que traz uma espécie de universo paralelo com a web 2.0 e ressignifica ações, o convívio, a comunicação em si e introduz aos poucos seu próprio vocabulário. Essa reformulação é caracterizada por Levy (2009) como cibercultura e inclui inúmeros desafios provenientes de modalidades comunicacionais mais ágeis que têm como território o ciberespaço, um ambiente virtual capaz de suportar diversos sistemas de comunicação concomitantes. Também recebe destaque do autor a necessidade de adequação da escola, pois "uma vez que os indivíduos aprendem cada vez mais fora do sistema acadêmico, cabe aos sistemas de educação implantar procedimentos de 
reconhecimento dos saberes e savoir-faire adquiridos na vida social e profissional". (LEVY, 2009, p. 175.)

As infovias, caminhos que comunicam os computadores em rede, encarregam-se da ubiquidade dos contatos e tornam alguns conhecimentos até então retidos em fontes específicas, universais. Saberes exclusivos e territorializados agora são compartilhados e podem ser acessados em qualquer lugar e a qualquer momento. Conjecturando sobre o assunto e nomeando os sujeitos das atuais gerações de Polegarzinhas e Polegarzinhos em virtude da movimentação frenética do polegar na manipulação de aparelhos celulares, Serres (2011) sinaliza que com o advento da internet os sujeitos polissêmicos, cercados pela distribuição de informações e conhecimentos em rede característica da cultura digital, muitas vezes são indiferentes aos saberes estanques nos moldes convencionais. Assim, o repertório divulgado e mediado pelos professores e concentrado na escola, por exemplo, agora é veiculado e acessado globalmente (SERRES 2011; MARTÍN-BARBERO, 2014). Esse cenário não necessariamente sepulta o sistema educativo, mas como já nos havia indicado Levy (2009), encaminha ao menos a uma releitura da sua funcionalidade.

Relações verticalizadas menosprezam o processo de ensino-aprendizagem e limitam o diálogo, agravando o quadro. A expansão do conhecimento para além da escola requer uma revisão do seu processo de comunicação que, segundo Martín-Barbero (2000), é um problema a ser resolvido antes de discutirmos a respeito dos meios. $\mathrm{O}$ autor denomina de ecossistema comunicativo as tessituras que estabelecemos com as tecnologias, que vão desde sua utilização corriqueira em operações bancárias à dispersão da informação que por meio de vários dispositivos se distribui e descentraliza indistintamente. Os jovens inseridos nessa multiplicidade são mais afetados e interagem com naturalidade nesse ecossistema, exercendo diferentes maneiras de relação com o mundo. Os jogos culturais encontram-se nesse bojo; legitimá-los e identifica-los pode facilitar o trabalho da escola e aproximar seus integrantes, mas, para tanto, precisamos aquecer os debates.

\section{O CONTEXTO SOCIOCULTURAL E A INVASÃO TECNOLÓGICA NA ESCOLA}

A apresentação do contexto sociocultural no qual se insere uma pesquisa ou mesmo se dialoga sobre uma temática pode auxiliar na análise de suas possíveis contribuições e focalizar sua pertinência. Assim, nesta sessão do artigo serão aliados referenciais teóricos que tratam da cultura, da comunicação e da educação em tempos de ebulição das TICs, tendo em vista algumas transformações já verificadas e a serem concretizadas na sociedade a partir dessa conjugação de acordo com a alegação dos autores.

Ao analisar a estruturação da sociedade em rede, organizada a partir da década de 1960 e suportada por TICs, Castells (2006) realça que, de fato, o viés tecnológico está em acelerada ascensão como elemento social, mas afirma que esse paradigma não determina a sociedade, mas o contrário, sim: a sociedade manipula os recursos desenvolvidos nesse contexto para satisfazer as necessidades dela em compatibilidade com valores e interesses de

\begin{tabular}{l|l|l|l|l|l|l} 
(C) ETD -Educ. Temat. Digit. & Campinas, SP & v.18 & n.1 & p. 122-135 & jan./abr.2016 & ISSN 1676-2592
\end{tabular}


seus membros. Para o autor, a questão tecnológica e a organização social articulam-se profundamente.

Castells (2006) acrescenta ainda a esse debate o caráter excludente das TICs, mas sinaliza de antemão que mesmo quando ausente no tocante aos recursos, a lógica pertinente a essas tecnologias já afeta a sociedade no que tange à globalização que promove um fenômeno que veladamente forja outros aspectos conceituais. A cultura da sociedade em rede é então marcada pelo intercâmbio de mensagens multimídia, os hipertextos, que configuram formas de comunicação diferentes, pois "na sociedade em rede, a virtualidade é a refundação da realidade através de novas formas de comunicação socializável”. (CASTELLS, 2006, p. 24.)

Com o intuito de mensurar a agudeza de tal expansão tecnológica, Serres (2011) aponta três revoluções ocorridas nas sociedades ocidentais, demarcando as transições sofridas pelos processos de comunicação: a da oralidade para registros escritos, destes para a escrita impressa e do impresso ao virtual. Expõe também que as consequências políticas, cognitivas e sociais alocadas nessas transposições deflagraram outros pertencimentos. Sustentando ainda o diálogo com Serres (2011) nos endereçamos aos adventos da escrita e da impressão com o status de ameaça à memória, pois todas as informações restritas à oralidade e seguidamente aos manuscritos seriam transferidas aos livros, e a impressão absolveria a necessidade de memorização. Para o autor, a disseminação das tecnologias de informação e comunicação corresponde a mais uma variante, outra transição, que repercutirá em mudanças adaptativas para a adequação delas no aspecto pedagógico, principalmente; estaríamos nos defrontando com uma ruptura paradigmática que populariza e desloca a informação e o conhecimento.

É conveniente que a alternância nas formas de comunicação exposta por Serres (2011) seja reforçada pela perspectiva do saber na era da informação traçada por Martín-Barbero (2014) que aborda a presença da tecnologia hoje na sociedade não apenas como um acervo material, mas como instauração de novos modos de percepção e de linguagem. Sobre os efeitos desse fenômeno, o autor explana:

O que a trama comunicativa da revolução tecnológica introduz em nossas
sociedades não é, pois, tanto uma quantidade inusitada de novas máquinas, mas um
novo modo de relação entre os processos simbólicos - que constituem o cultural -e
as formas de produção e distribuição de bens e serviços. A "sociedade da
informação" não é, então, apenas aquela em que a matéria-prima mais cara é o
conhecimento, mas também aquela em que o desenvolvimento econômico, social e
político encontra-se intimamente ligado à inovação, que é o novo nome da
criatividade e da invenção. (MARTÍN-BARBERO, 2014, p. 79.)

O conhecimento a que os autores se referem, confinado nos livros durante muito tempo e centralizado sob o domínio de poucos, atualmente se encontra pulverizado por causa das difusões promovidas pelos diferentes meios comunicacionais. Um inusitado panorama cultural então se coloca; indivíduos repletos dos saberes-mosaico (MARTÍN-BARBERO, 2014), distribuídos largamente nos ambientes que frequentam, vão à escola, cuja reação é "entrincheirar-se em seu próprio discurso, pois qualquer outro modo de saber é percebido pelo sistema escolar como um atentado direto à sua autoridade" (MARTÍN-BARBERO, 2014, p. 81). É possível que estejamos diante de um choque cultural no que tange à 
translocação do conhecimento, produzindo como resultado certa insegurança com relação à cultura escolar, que talvez por não contar com artifícios imediatos de controle e mudança, ou por não captar amplamente a complexidade do fenômeno, estigmatiza sua disseminação.

O reflexo dessa conduta é a ignorância dos processos que reestruturam as linguagens, as escrituras e as narrativas, levando alunos que possuam outras modalidades além daquelas tradicionalmente trabalhadas a não estabelecerem uma relação que faça sentido com a instituição escolar, exibindo inclusive uma concepção de leitura não condizente com a dos professores. Martín-Barbero (2014) enfatiza ainda que "meios e tecnologias são para os mais jovens lugares de um desenvolvimento pessoal que, por mais ambíguo e até contraditório que seja, eles converteram no seu modo de estar juntos e de expressar-se". (p. 120)

Ao discorrer sobre os desafios educacionais na sociedade multimidiática e munida de estudos provenientes do grupo de pesquisa sobre o tema, Guimarães (2006) contribui com a discussão quando analisa as possibilidades de confronto entre os discursos da tevê e os da escola, buscando elucidar os mecanismos de filiação e resistência de cada um, destacando que os tipos de configuração textual de ambos (narração e descrição respectivamente) podem estar relacionados a esses fenômenos. Mesmo diante da incerteza do confronto, mas alerta às dissonâncias, a autora destaca que entre os discursos "há diferenças significativas que não podem ser desprezadas pela escola, na perspectiva de favorecer a leitura crítica do texto contemporâneo". (GUIMARÃES, 2006, p. 173.)

Assim como a tevê, abordada na tese referida, já enunciamos até aqui outras transversalidades tecnológicas que também praticam e propõem diferentes linguagens, instaurando remodelações culturais importantes das quais não parece interessante que a escola se abstenha. $\mathrm{O}$ fato é que a mesma autora sinaliza a necessidade de adequação pedagógica das mediações para que haja uma apropriação/leitura crítica dos textos contemporâneos, com a atenção para a leitura sob diferentes perspectivas, levando em conta sua produção e afastando o viés puramente técnico, que altera os meios, mas mantém antigas formas.

Sobre a temática, Martín-Barbero (2014) discute a pluralidade dos alfabetos e projeta as alfabetizações fonética e eletrônica como exigências futuras à educação, que segundo o autor ao articulá-las será "capaz de formar cidadãos que saibam ler tanto jornais impressos como televisivos, videogames, videoclipes e hipertextos". (MARTÍN-BARBERO, 2014, p. 52.) Acatar a oportunidade de ampliação do fazer educativo, garantindo a certificação da atual tecnologização como fenômeno social, é respeitar, portanto, o momento cultural vivenciado pelos jovens, pois

[...] somente a partir da assunção da tecnicidade midiática como dimensão estratégica da cultura, a escola poderá se inserir nas novas figuras e campos de experiência em que se processam os intercâmbios entre escrituras tipográficas, audiovisuais e digitais, entre identidades e fluxos, assim como entre movimentos cidadãos e comunidades virtuais. (MARTÍN-BARBERO, 2014, p. 44.) 
Atentar para os comportamentos juvenis associados à eleição do ambiente virtual como lugar de expressão de suas narrativas facilita a aproximação da ideia de modificação da sociabilização. A exploração desse terreno pode providenciar maior intimidade das instituições sociais com os efeitos das transformações culturais. Como recurso para dirimir os bloqueios e ruídos na comunicação dos jovens com a sociedade, acrescenta Martín-Barbero (2014, p.120):

(...) devolver aos jovens espaços nos quais possam se, manifestar estimulando práticas de cidadania é o único modo pelo qual uma instituição educativa, cada vez mais pobre em recursos simbólicos e econômicos, pode reconstruir sua capacidade de socialização. Cortar o arame farpado dos territórios e disciplinas, dos tempos e discursos, é a condição para compartilhar, e fecundar mutuamente, todos os saberes, da informação, do conhecimento e da experiência das pessoas; e também as culturas com todas as suas linguagens, orais, visuais, sonoras e escritas, analógicas e digitais.

Nesta lógica, o sistema educativo, mais precisamente simbolizado como território de concentração do saber em uma visão anterior à propulsão tecnológica, sofre um destronamento e depara com uma certa vulgarização dos conhecimentos que lhe eram pertinentes e exclusivos. A crise da dessacralização do saber escolar e erudito, discutida por Serres (2011) e Martín-Barbero (2014), pode ter sido disparada em função do fenômeno descrito. O segundo autor citado destaca ainda que essa reconfiguração estaria abalando o modelo de aprendizagem por completo, descentralizando o livro e contrariando as ordenações e sequências cotidianas, além da atividade e da passividade no tocante à divulgação e à apropriação dos conteúdos. Aprende-se tanto fora quanto no interior da escola, sem tempo, lugar ou idade específicos.

O excesso de informação gerado pelos fluxos e cruzamentos das mídias em tempo real, no entanto, imbrica algumas vezes na obrigatoriedade velada da fabricação de opinião que seria o produto de tais contatos, cuja urgência instauraria um quadro de superficialidade, os quais na crítica de Larrosa (2002) devem-se ao exagero de estímulos e à redução drástica do tempo. Os atravessamentos e a experiência efetiva são, nessa ótica, cada vez mais raros, pois a fugacidade com que ocorrem as emissões e recepções impede o aproveitamento daquilo que está sendo falsamente captado. Sobre essa dinâmica, o autor completa:

A velocidade com que nos são dados os acontecimentos e a obsessão pela novidade, pelo novo, que caracteriza o mundo moderno, impedem a conexão significativa entre acontecimentos. Impedem também a memória, já que cada acontecimento é imediatamente substituído por outro que igualmente nos excita por um momento, mas sem deixar qualquer vestígio. O sujeito moderno não só está informado e opina, mas também é um consumidor voraz e insaciável de notícias, de novidades, um curioso impenitente, eternamente insatisfeito. Quer estar permanentemente excitado e já se tornou incapaz de silêncio. Ao sujeito do estímulo, da vivência pontual, tudo o atravessa, tudo o excita, tudo o agita, tudo o choca, mas nada lhe acontece. Por isso, a velocidade e o que ela provoca, a falta de silêncio e de memória, são também inimigas mortais da experiência. (LARROSA, 2002, p. 23.)

Nessa mesma linha, Martín-Barbero (2014) argumenta que em virtude da ausência de referenciais soberanos, os jovens de hoje são mais suscetíveis a instabilidades subjetivas e identitárias. Trata-se de um sujeito voltado para si, pois as certezas em torno dos diversos planos nos quais está inserido são mínimas. A compatibilidade entre este indivíduo e as 
práticas escolares requer que a escola legitime o comportamento dele e as maneiras de convivência por ele admitidas, pois o mesmo autor enfatiza que estamos diante de um novo espaço comunicacional não constituído por aglomerados humanos, mas organizado pela conectividade. Sendo assim, as demandas escolares têm outras necessidades.

O conhecimento mínimo a respeito do aluno pode ser útil nas relações de aprendizagem. Podemos estar diante de uma confluência entre o que insiste Freire (2014) sobre a importância de se oferecer densidade cultural aos processos de alfabetização, partindo-se de palavras geradoras emergidas do universo discente, e os novos modos de estar juntos conjecturados por Martín-Barbero (2014) e Serres (2011), que para serem decifrados pela escola, primeiramente precisam ser revelados.

Sentenciando o fim da era do saber, Serres (2011) comenta a dinâmica pedagógica ainda presente nas salas de aula e ressalta o professor como porta-voz do conhecimento dos livros, o qual se tornou inaudível, pois com a banalização e a oferta dos mesmos saberes por outras vias, criam-se inúmeras oportunidades de encontro, o que submete a ocasião em questão a outros planos.

Estaria o sistema educativo fadado ao desaparecimento? A função docente talvez esteja em metamorfose, pois mesmo que se compactue com a ideia de deslocamento do saber, há de se administrá-lo e adensá-lo para fins letivos, a partir de uma triagem do que realmente é pertinente. O professor pode ter então seu papel reformulado nesse sentido. A pedagogia estará provavelmente a serviço da construção de fazeres docentes nesse prognóstico, que poderá consistir basicamente no gerenciamento dos conteúdos.

De acordo com Martín-Barbero (2014), atravessamos uma profunda reorganização dos modelos de socialização que apontam especialmente para a lógica do capital. Nesse panorama, a escola, silenciosa e por enquanto incapaz de analisar as proporções das mudanças culturais que emergem, mostra-se omissa e aquiescente - o que ironicamente a convoca a cúmplice do engendramento. $\mathrm{O}$ autor acrescenta que elidir a existência e a utilidade pedagógica ou simplesmente rechaçar as tecnologias que porventura invadam diariamente as salas de aula são comportamentos que podem fortalecer a sua aplicação próhegemônica, favorável a interesses políticos.

\section{A NECESSIDADE DO DIÁLOGO E OUTRAS CONSIDERAÇÕES}

Aproveitando o ensejo, afastando discretamente a tecnologia como cerne e trazendo as dificuldades que entravam as mudanças no ensino de maneira geral, destinamos a atenção ao posicionamento de Krasilchik (1992, 2000), que realizando uma revisão das intenções de reforma do ensino de Ciências, aponta que as tendências, os objetivos e as modalidades praticadas refletem as mudanças da sociedade, atendendo a um jogo de interesses que muito mais se aproxima de questões políticas do que propriamente educacionais. Indica a autora que o atual movimento de reformulação no Brasil inclina-se a centralizar no Estado as normas e os regulamentos, enveredando por um viés no qual "mantém-se um ensino precário com professores que enfrentam nas escolas problemas de sobrecarga, de falta de recursos e de 
determinações que deveriam seguir sobre as quais não foram ouvidos". (KRASILCHIK, 2000, p. 87.)

À medida que sua atividade é contornada por exigências governamentais que focam a concorrência de mercado, o desempenho docente/discente e o nível de qualidade da educação passam a ser aferidos por exames externos que, em geral, apresentam uma estrutura avaliativa não condizente com a modalidade de ensino. Apesar da inconsistência, os resultados são veiculados como confiáveis, traduzindo em percentuais toda a complexidade de um processo e construindo uma representação social equivocada da escola.

A globalização imputa diferentes ordens sociais que pluralizam a participação do sujeito e maximizam o seu papel de acordo com uma política que em alguns aspectos, isenta o Estado e responsabiliza o cidadão. Imerso nessa realidade, o ensino de Ciências na atualidade, segundo Krasilchik (2000), caracteriza-se como uma atividade de implicações sociais, centralizada nas universidades e pautada nos recursos tecnológicos como ferramentas didáticas. É oportuno frisar, portanto, que diante desse painel a escassez dos debates esvazia a atividade docente e inviabiliza o professor de "nas atuais condições de trabalho criar um clima de liberdade intelectual, que não limite a sua atividade a exposições, leitura ou cópia de textos”. (KRASILCHIK, 2000, p. 88.)

Krasilchik (2000) nos revela ainda que qualquer reforma educacional deveria discutir os dilemas que afetam a prática docente, na assunção de mudanças reais na qualidade. A investigação científica formaliza essa e muitas outras inquietações, buscando parâmetros e soluções viáveis à construção de um ensino de ciências emancipatório. Sendo assim, a autora ressalta: "Se, por um lado, é imprescindível a intensificação das relações entre a escola e a comunidade para a formação de cidadãos atuantes, por outro, é absurdo ignorar o que têm a dizer os cientistas e pesquisadores e o que se conhece hoje sobre os processos de reforma curricular". (p. 90). Faz sentido o pacto com a autora quanto à afirmação da conveniente fusão de esforços direcionados ao alcance de atuações mais dilatadas no ensino, pois entremear competências pode gerar estratégias de fortalecimento e reforma.

A concepção de trabalho docente é complexa e multifacetada. Para Tardif e Lessard (2013), essa atividade pode ser considerada como trabalho interativo, pois relaciona o trabalhador ao objeto humano e às diversas especificidades que ele exige, modificando a natureza do trabalho e a atividade do trabalhador. Trata-se, portanto, de um grande fluxo entre as partes, que estão em constante transformação como efeito das intervenções mútuas. Nóvoa (2009) defende a instituição de práticas como lugar de reflexão e formação, desvia do debate puramente academicista e centraliza a análise no terreno profissional, perseguindo a importância do desenvolvimento pessoal e profissional do professor. Nessa perspectiva, a formação não seria meramente o acúmulo de conhecimentos e técnicas, mas a reflexividade crítica sobre as práticas e a (re)construção permanente de uma identidade pessoal. A questão identitária está imbricada na profissionalidade docente e dissociá-las pode levar a uma distorção do papel do professor no contexto social em que se desenvolve. 
A articulação entre saberes teórico-práticos ilumina a construção da identidade docente. Para esse diálogo convocamos Garcia (2010), destacando as características primordiais relacionadas a essa construção, que partem dos conteúdos pertinentes, passam pela aprendizagem informal, pela socialização prévia - que se refere ao período de observação dos professores na qualidade de alunos - e culmina com a importância das emoções como elemento essencial.

Diante da gama de componentes do trabalho docente em uma visão bastante amplificada, a reflexão e os recortes tornam-se uma exigência; a análise cuidadosa do contexto e o respeito aos saberes trazidos pelo aluno são fatores que oportunizam a adoção de metodologias e ações mais adequadas à realidade de cada nicho educativo, tornando a tarefa do professor mais fluídica e acessível, com possibilidades transformadoras, pois de acordo com Freire (2014, p. 109) "o espaço pedagógico é um texto para ser constantemente lido, interpretado, escrito e reescrito".

Distante de um discurso de solução de problemas, é oportuno frisar que os sujeitos envolvidos nos processos pedagógicos precisam estar na centralidade, não os meios comunicacionais. No atual panorama, a habilidade dos professores na apropriação das Tecnologias de Informação e Comunicação (TICs) em suas atividades é um diferencial, e uma formação docente voltada a esse interesse poderia aprimorá-la. 


\section{REFERÊNCIAS}

CASTELLS, Manuel (Org.). A sociedade em rede: do conhecimento à política. In: CASTELLS, Manuel; CARDOSO, Gustavo. A sociedade em rede: do conhecimento à ação política. Belém: Imprensa Nacional: Casa da Moeda, 2006, p. 17-30.

FERNANDES, Gláucia Braga Ladeira. Universidade e inserção profissional: um estudo de egressos das licenciaturas da faculdade de formação de professores da UERJ. 2011. $157 \mathrm{f}$. Dissertação (Mestrado em Educação) - Faculdade de Educação, Universidade do Estado do Rio de Janeiro, Niterói, RJ, 2011. Disponível em: < https://goo.gl/zuoaOb>. Acesso em: 02 jul. 2015.

FONTOURA, Helena Amaral. Residência Pedagógica: investigação-ação com professores egressos da Faculdade de Formação de Professores da UERJ. Revista de Educação Pública, Cuiabá, MT, v. 20, n. 43, p. 307-322. maio/ago. 2011. Disponível em: <http://goo.gl/b8Y77J >. Acesso em: 02 jul. 2015. ISSN 0104-5962.

FREIRE, Paulo. A pedagogia da autonomia. 49. ed. Rio de Janeiro: Paz \& Terra, 2014.

GARCIA, Carlos Marcelo. O professor iniciante, a prática pedagógica e o sentido da experiência. Formação Docente, Belo Horizonte, MG, v. 03, p. 11-49. ago./dez. 2010. Disponível em: 〈 http://goo.gl/7IQtOr〉. Acesso em: 02 jul. 2015. ISSN 2176-4360.

GUIMARÃES, Gláucia Campos. A articulação de linguagens na TV: questões educacionais para a sociedade multimidiática. 2006. Tese (Doutorado em Educação) Faculdade de Educação, Universidade do Estado do Rio de Janeiro, Rio de Janeiro, RJ. Disponível em:

< http://goo.gl/XwFFzj>. Acesso em: 02 jul. 2015.

KRASILCHIK, Myriam. Caminhos do ensino de ciências no Brasil. Em Aberto, Brasília, DF, v. 11, n. 55, p. 03-08. jul./set. 1992. Disponível em: 〈http://goo.gl/156Spt >. Acesso em: 02 jul. 2015. ISSN 2176-6673.

KRASILCHIK, Myriam. Reformas e realidade: o caso do ensino das ciências. São Paulo em Perspectiva, São Paulo, SP, v. 14, n. 01, p. 85-93. 2000. Disponível em: < http://goo.gl/muA6Z3 >. Acesso em: 02 jul. 2015. ISSN 1806-9452.

LARROSA, Jorge Bondía. Notas sobre a experiência e o saber de experiência. Tradução de João Wanderley Geraldi. Revista Brasileira de Educação, Rio de Janeiro, RJ, n. 19, p. 2028, jan./abr. 2002. Disponível em: 〈 http://goo.gl/MKAK9U〉. Acesso em: 02 jul. 2015. ISSN $1413-2478$.

LEVY, Pierre. Cibercultura. 2. ed. São Paulo: Editora 34, 2009.

MARTÍN-BARBERO, Jesus. A comunicação na educação. São Paulo: Contexto, 2014.

MARTÍN-BARBERO, Jesus. Desafios culturais da comunicação à educação. Comunicação

\& Educação, São Paulo, SP, v. 18, p. 07-14. maio/ago. 2000. Disponível em: < http://goo.gl/H3kz1B >. Acesso em: 02 jul. 2015. ISSN 0104-6829. 
NÓVOA, Antonio. Para uma formação de professores construída dentro da profissão. In: NÓVOA, António (Org.) Professores: imagens do futuro presente. Lisboa: Educa, 2009, p. 25-46. Disponível em: < http://goo.gl/7uQKN3>. Acesso em: 02 jul. 2015.

TARDIF, Maurice; LESSARD, Claude. O trabalho docente: elementos para uma teoria da docência como profissão de interações humanas. 8. ed. Petrópolis, RJ: Vozes, 2013.

SERRES, Michel. Polegarzinha: uma nova forma de viver em harmonia, de pensar as instituições, de ser e de saber. Rio de Janeiro: Bertrand Brasil, 2013.

\section{Como citar este documento:}

SIQUEIRA, Graziele Cancio; Fontoura, Helena Amaral da. A invasão das Tecnologias de Informação e comunicação nas escolas e o diálogo necessário. ETD - Educação Temática Digital, Campinas, SP, v. 18, n. 1, p. 122-135, abr. 2016. ISSN 1676-2592. Disponível em:

<http://periodicos.sbu.unicamp.br/ojs/index.php/etd/article/view/8637541>. Acesso em: 05 abr. 2016. doi: <http://dx.doi.org/10.20396/etd.v18i1.8637541>. 